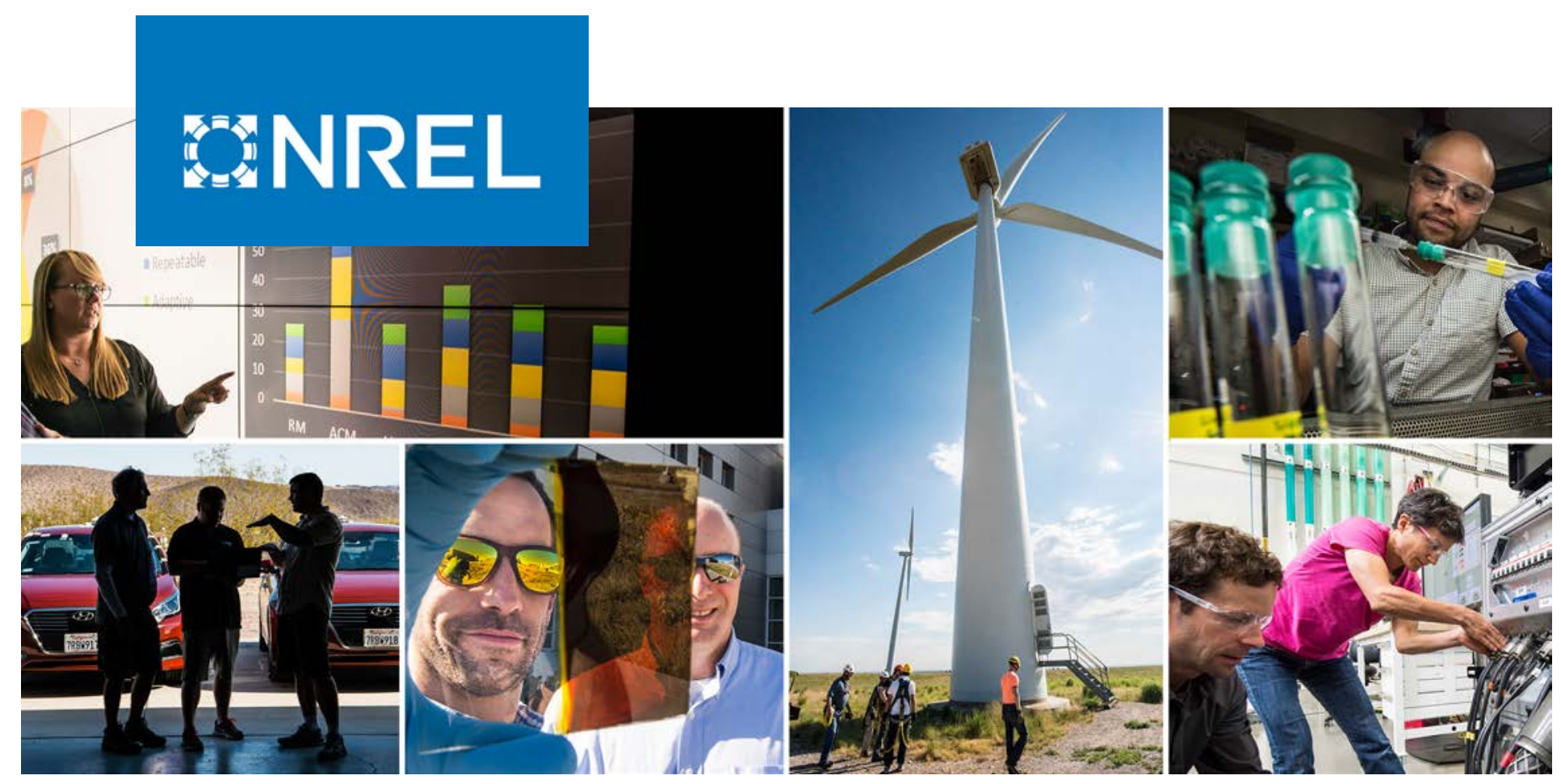

\title{
Developing a Framework for Reference Cell Standards for PV Resource Applications
}

Aron Habte, ${ }^{1}$ Manajit Sengupta, ${ }^{1}$ Yu Xie, ${ }^{1}$ Mike Dooraghi, ${ }^{1}$ Ibrahim Reda, ${ }^{1}$ Anton Driesse, ${ }^{2}$ Christian Gueymard, ${ }^{3}$ Stefan Wilbert, ${ }^{4}$ and Frank Vignola ${ }^{5}$
${ }^{1}$ National Renewable Energy Laboratory
${ }^{2}$ PV Performance Labs
${ }^{3}$ Solar Consulting Services
${ }^{4}$ German Aerospace Center (DLR)
${ }^{5}$ University of Oregon

NREL is a national laboratory of the U.S. Department of Energy Office of Energy Efficiency \& Renewable Energy

Operated by the Alliance for Sustainable Energy, LLC

This report is available at no cost from the National Renewable Energy Laboratory (NREL) at www.nrel.gov/publications.
Technical Report

NREL/TP-5D00-72599

December 2018 


\title{
GNREL
}

\section{Developing a Framework for Reference Cell Standards for PV Resource Applications}

\author{
Aron Habte, ${ }^{1}$ Manajit Sengupta, ${ }^{1}$ Yu Xie, ${ }^{1}$ Mike Dooraghi, ${ }^{1}$ \\ Ibrahim Reda, ${ }^{1}$ Anton Driesse, ${ }^{2}$ Christian Gueymard, ${ }^{3}$ \\ Stefan Wilbert, ${ }^{4}$ and Frank Vignola ${ }^{5}$ \\ ${ }^{1}$ National Renewable Energy Laboratory \\ ${ }^{2}$ PV Performance Labs \\ ${ }^{3}$ Solar Consulting Services \\ ${ }^{4}$ German Aerospace Center (DLR) \\ ${ }^{5}$ University of Oregon
}

\section{Suggested Citation}

Habte, Aron, Manajit Sengupta, Yu Xie, Mike Dooraghi, Ibrahim Reda, Anton Driesse, Christian Gueymard, Stefan Wilbert, and Frank Vignola. 2018. Developing a Framework for Reference Cell Standards for PV Resource Applications. Golden, CO: National Renewable Energy Laboratory. NREL/TP-5D00-72599.

https://www.nrel.gov/docs/fy19osti/72599.pdf.

NREL is a national laboratory of the U.S. Department of Energy Office of Energy Efficiency \& Renewable Energy Operated by the Alliance for Sustainable Energy, LLC

This report is available at no cost from the National Renewable Energy Laboratory (NREL) at www.nrel.gov/publications.

Contract No. DE-AC36-08GO28308
Technical Report

NREL/TP-5D00-72599

December 2018

National Renewable Energy Laboratory 15013 Denver West Parkway Golden, CO 80401

303-275-3000 • www.nrel.gov 


\section{NOTICE}

This work was authored in part by the National Renewable Energy Laboratory, operated by Alliance for Sustainable Energy, LLC, for the U.S. Department of Energy (DOE) under Contract No. DE-AC36-08G028308. Funding provided by U.S. Department of Energy Office of Energy Efficiency and Renewable Energy Solar Energy Technologies Office. The views expressed herein do not necessarily represent the views of the DOE or the U.S. Government.

This report is available at no cost from the National Renewable Energy Laboratory (NREL) at www.nrel.gov/publications.

U.S. Department of Energy (DOE) reports produced after 1991 and a growing number of pre-1991 documents are available free via www.OSTI.gov.

Cover Photos by Dennis Schroeder: (clockwise, left to right) NREL 51934, NREL 45897, NREL 42160, NREL 45891, NREL 48097, NREL 46526.

NREL prints on paper that contains recycled content. 


\section{Acknowledgments}

We are grateful to the U.S. Department of Energy Solar Energy Technologies Office and its photovoltaic and systems integration subprograms for supporting this research. Specifically, we acknowledge Dr. Tassos Golnas, Dr. Dave Rench-McCauley, Dr. Lenny Tinker, Dr. Rebecca Jones-Albertus, and Dr. Charlie Gay for their support and encouragement. 


\section{List of Acronyms}

BORCAL Broadband Outdoor Radiometer Calibration

DHI

DNI

Diffuse horizontal irradiance

GHI

GTI

Direct normal irradiance

IEC

Global horizontal irradiance

Global total irradiance

ISO

NREL

POA

PV

International Electrotechnical Commission

International Organization for Standardization

National Renewable Energy Laboratory

SI

Plane of array

Photovoltaic

WRR

International Systems of Units

World Radiometric Reference 


\section{Executive Summary}

Quantifying and predicting electricity production from photovoltaic (PV) systems is based on measured or modeled irradiance data. These solar resource data consist of global horizontal irradiance, global tilted irradiance, direct normal irradiance, and diffuse horizontal irradiance, which are either derived from satellite observations validated against ground-based measurements or directly obtained from ground-based measurements. The ground-based measurements are made using thermopile or photodiode radiometers.

For a PV plant, the efficiency of the energy production is verified by comparing measured output with the modeled production, which is computed using either modeled or measured irradiance data. Thus, plant performance assessments typically include the uncertainty of the transposition and, in some cases, decomposition of a given irradiance to convert to the appropriate plane-ofarray (POA) irradiance corresponding to the orientation of the PV installation. Additionally, the various types of uncertainty in radiometric measurements or the modeled irradiance and the PV module specifications influence the model results and thereby further increase the uncertainty. An alternative method of assessing the PV system performance has been to use reference cells to measure the "PV resource." When used to calculate PV performance ratios, there are inherent systematic differences between radiometers and reference cells, such as spectral, directional, temperature, time responses, nonstability, and nonlinearity differences. Reference cells tend to mimic the performance and characteristics of a PV module more closely. In this report, a framework is proposed to develop standards that will better quantify and characterize the use of reference cells for PV resource measurements.

The measurement from an appropriate reference cell in the POA correlates closely with the plant performance, reduces the number of modeling steps needed to simulate PV performance, and hence reduces the uncertainties of the comparisons. Because technologically matched reference cells and PV modules respond similarly to each wavelength of light that composes the incident solar radiation, the uncertainty associated with the changing spectral distribution of incident radiation during the day and year can be greatly reduced. This will reduce the overall uncertainty in estimated PV performance. The same can be said for the angle-of-incidence effects because the reference cells are deployed in the same POA as the PV module. At that point, the main sources of uncertainty are in modeling the temperature effect differences between the reference cells and the PV module and accounting for the difference between the short-circuit current monitored by the reference cells and max power point current and voltage at which the PV module operates. These sources of uncertainty are also associated with typical irradiance measurements made by pyranometers and pyrheliometers; however, typical irradiance measurements also include uncertainties associated with the spectral mismatch between thermopile or photodiode pyranometers and the PV module, which are minimized with the use of reference cells.

To enhance the use of reference cells for resource assessment, we identify the necessary data, characteristics, and calibration methodologies of reference cells and how to standardize the use of these data and methods. Further, as we develop this framework, the classification of reference cells will be essential to provide guidance for selecting PV reference cells appropriate for a specific application. As we address the calibration and sources of uncertainties of reference cells, 
classification schemes and expected limits of performance with respect to certain parameters become important.

Moreover, this report discusses possible technical and analytical challenges that might be encountered as these methodologies are developed. The development of these methodologies is also needed for other initiatives, such as the use of reference cell measurements directly in performance or economic models. It should be possible to meet various application needs with reference cells through the verification, acceptance, and implementation of reference cells for resource assessments. 


\section{Table of Contents}

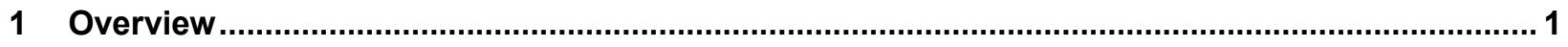

2 Developing a Framework for New Reference Cell Standards ...................................................... 2

2.1 Standard Spectra for a Wide Range of Standard Atmospheres .................................................. 3

2.2 Outdoor Process for Reference Cell Calibration and Characterization........................................ 5

2.2.1 Develop Standard Filter for Reference Cells Calibration to PV Resource...................... 1

2.3 Develop Standardized Outdoor Process to Transfer Calibration from Primary Reference Cell to

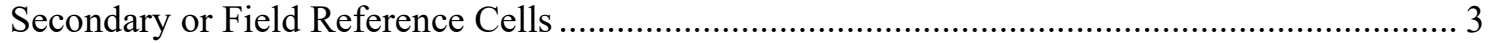

2.4 Develop Best Practices for Field Deployment of Reference Cells............................................. 4

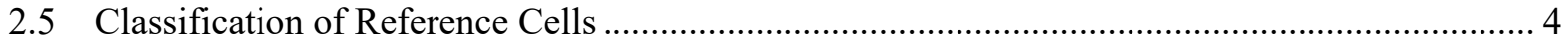

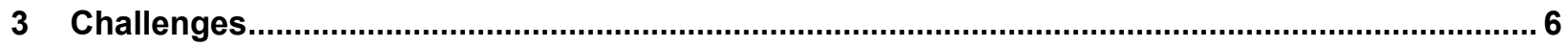

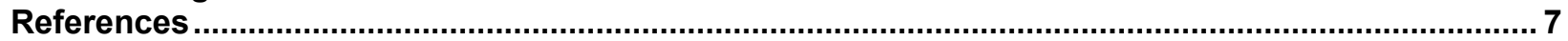




\section{List of Figures}

Figure 1. Flowchart demonstrating essential required standards and their linkage .................................. 3

Figure 2. Additional spectra GTI $\left(20^{\circ}\right)$ obtained from [12] compared to the IEC standard spectrum for $37^{\circ}$

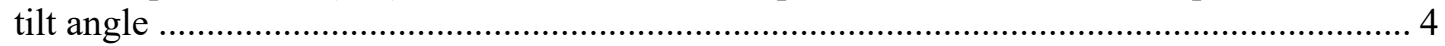

Figure 3. Absolute cavity pyrheliometer (left) and shaded diffuse pyranometer (right). Photos by Dennis Schroeder, NREL 22510 (left); and Tom Stoffel (right)...................................................... 0

Figure 4. Calibration result for reference cell and associated calibration uncertainty. Illustration by

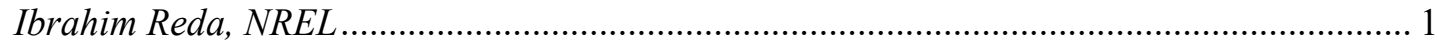

Figure 5. Flowchart illustrating the filter-based approach for reference cell calibration........................... 3 


\section{Overview}

Historically, solar irradiance measurements for outdoor photovoltaic (PV) performance monitoring has been carried out using either pyranometers, reference cells, or sometimes both. The results obtained with these options are not directly comparable, resulting in frequent discussions about which option is preferred [1], [2]. The PV community is increasingly interested in using reference cells that accurately quantify the solar resource available to a PV system for outdoor solar resource measurement and characterizing PV performance. The specific energy in the plane of array (POA) contained within the spectral range that a PV-based technology is sensitive to is referred to as the "PV resource." Fortunately, reference cells are readily available, but the methodologies and standards for how to use these sensors for outdoor applications are not well established. Therefore, current calibration and characterization approaches for these devices are applicable only for the spectral irradiance distribution under which they were configured. Because the incident spectral distribution changes with changes in atmospheric conditions, solar zenith angle, or PV geometry, the development of dynamic calibration methods is needed to characterize the sources of uncertainties of reference cells, similar to what is done with thermopile instruments. Alternatively, a different approach might also be considered. Because solar panel nameplate ratings and efficiencies are defined relative to a specific reference spectrum, the methodology used for the calibration of matching reference cells could match the methodology for defining the specifications of the solar panels. This is expected to provide increased relative accuracy when estimating PV module performance. Further, it is essential to outline and standardize the outdoor deployment procedures, maintenance requirements, verification procedures, and calibration frequencies to use of reference cells. Similarly, the International Electrotechnical Commission (IEC) Technical Committee 82 Working Group 2 has a series of standards (e.g., IEC 61853-1 to IEC 61853-4; see [3]-[6]) that can assist in estimating the actual energy production from field-deployed PV modules under various temperature, tilt, irradiance, and solar spectral distributions. Thus, the characterization challenges for PV reference cells and modules are similar, and the ultimate objectives are the same: achieving better prediction of energy production.

We intend to use these existing standards in the development of the framework and later during the development of the needed standards. Moreover, this project's framework includes the development of a classification of PV reference cells based on their specifications to provide guidance to the PV community so that the most appropriate reference cell can be selected to suit the users' applications.

The National Renewable Energy Laboratory (NREL) has long-standing leadership roles and involvements with ASTM, the International Commission on Illumination, the International Energy Agency, and IEC to advance developments in solar resource assessment and support solar energy stakeholder needs. Hence, NREL will initiate the development of these new standards. Such standards are expected to play a significant role in improving the durability and efficiency of solar energy products, increasing consumer confidence in the quality of these products, contributing to a better understanding of the availability of the PV resource for solar energy conversion systems, and reducing the cost of solar project development. 


\section{Developing a Framework for New Reference Cell Standards}

PV reference cells have been used to measure solar irradiance for outdoor PV performance monitoring applications. Comparisons between reference cells and pyranometers are stated in [1], wherein reference cells can lead to improved characterizations of PV performance and thereby reduce the cost of capital and levelized cost of energy. Following is a summary of the possible applications of reference cells:

1. PV reference cells can be used for prospecting. As stated in [1], [2], PV reference cells and the PV modules have close spectral matches that reduce the uncertainty in the available energy for conversion into electricity, which ultimately reduces the levelized cost of energy.

2. PV reference cells can be used for long-term system monitoring to estimate the service life and degradation of PV modules.

3. PV reference cells can be used for short-term system performance tests, including performance guarantee tests. Reference cells and PV modules tend to respond similarly to varying meteorological conditions [2].

4. PV reference cells can be used to conduct research into specific aspects of performances: bifacial modules, thin-film spectral gains, soiling, etc.

In this report, we list a few possible standards that could guide the PV community toward using PV reference cells for estimating the PV resource (Figure 1). As we start developing the actual framework, we will include additional standards as needed to complete the logical sequence of standards for use by the PV industry. 


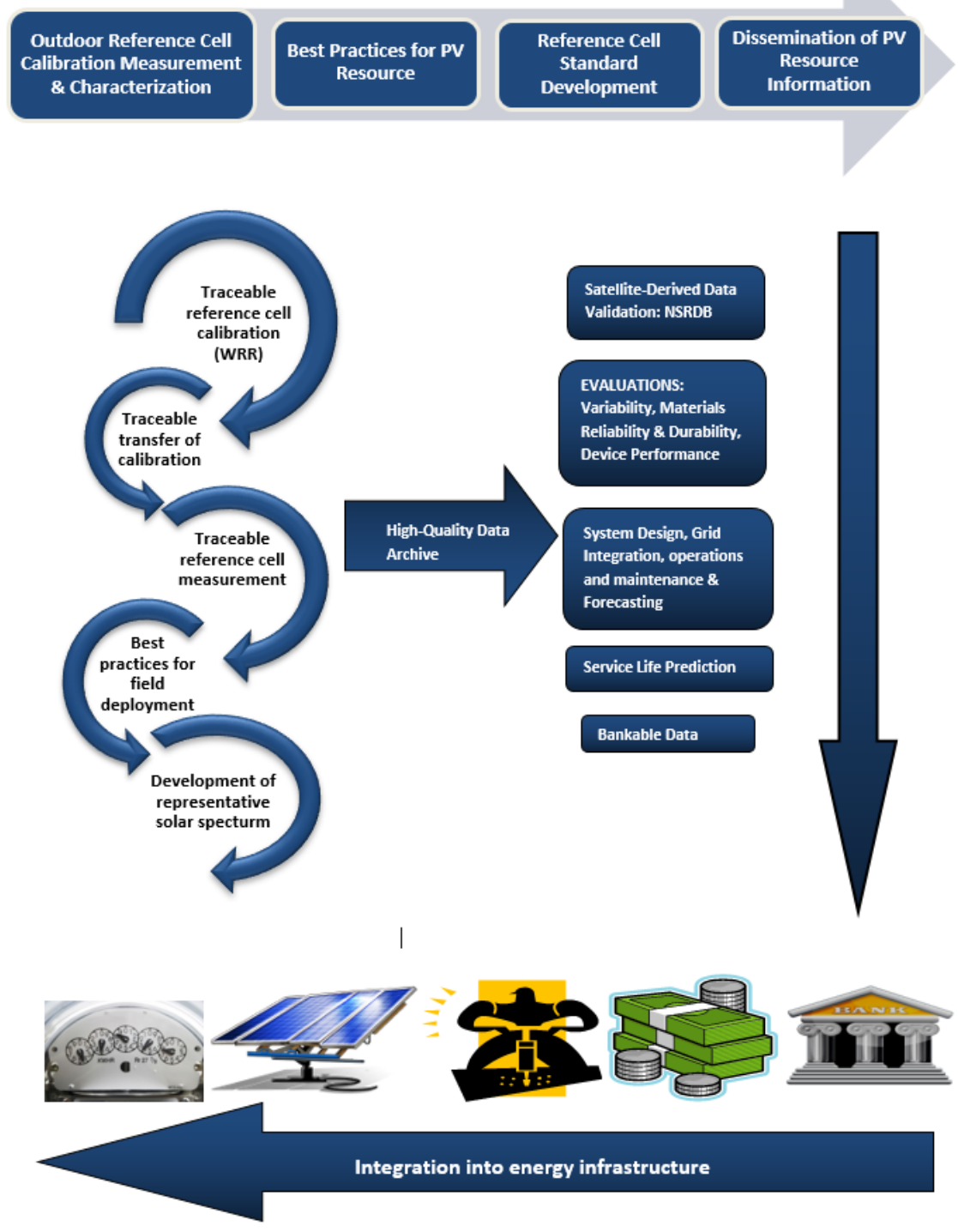

Figure 1. Flowchart demonstrating essential required standards and their linkage

\subsection{Standard Spectra for a Wide Range of Standard Atmospheres}

Existing international standards for reference broadband or ultraviolet spectra, such as ASTM G173, ASTM G177, ASTM G197, and IEC 60904-3 [7]-[19], are based on a single air mass, orientation, tilt, and set of atmospheric conditions. For instance, ASTM G173 is based on 1.5 air mass (AM1.5), sun-facing, $37^{\circ}$ tilt, and low-aerosol conditions. As stated in [11]-[14], these standards are essential for reporting standard testing conditions of materials such as reference cells. Appendix A of the new International Organization for Standardization (ISO) 9060:2018 standard for pyranometers contains a spectral responsivity standard. This standard is based on a mismatch factor between two spectral distributions at air masses of 1.5 and 5 and for various atmospheres. The comparison is made between an instrument that has no spectral dependence and an ideal instrument that changes responsivity with changes in spectral distributions. Air 
masses at 1.5 and 5 for various atmospheric conditions are used characterize the spectral dependence of the instrument. This characterization can be done theoretically as well as by measurement and describes the effect of changing spectrums on the instrument under study. A variety of reference climates are mentioned representing various climate zones. This information can then be used to characterize the spectral effects on reference cells at different tilts and orientations.

This work will follow the recommendation described in [12], which developed subordinate standard spectra representing various "characteristic" atmospheric conditions. These include both drier and moister climates than the U.S. Standard Atmosphere used in current standards as well as hazier aerosol conditions (more turbidity) or higher elevation. A total of eight supplementary atmospheric conditions are considered in [12], which demonstrate significant differences in global total irradiance (GTI), as shown in Figure 2.

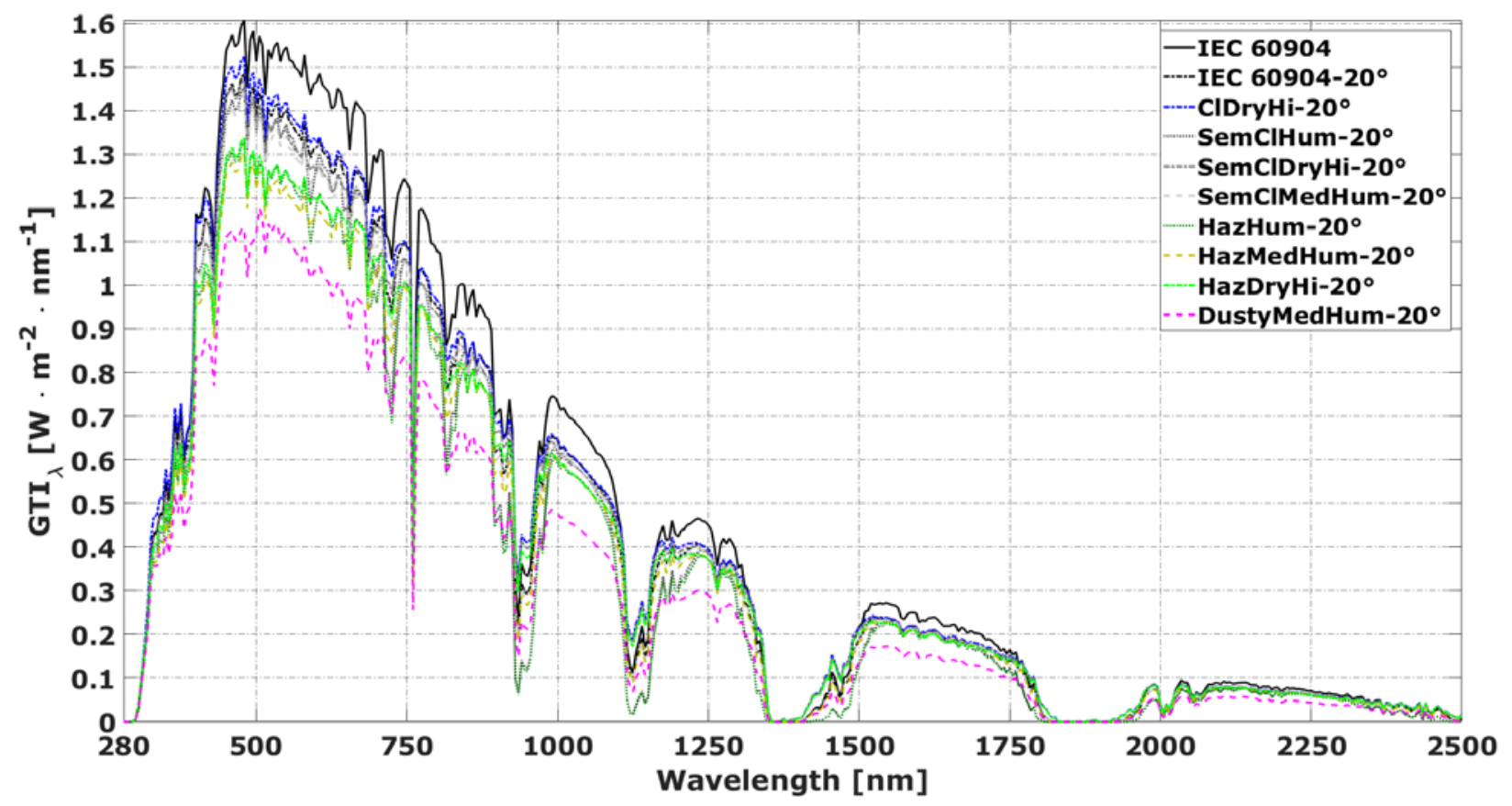

Figure 2. Additional spectra GTI $\left(20^{\circ}\right)$ obtained from [12] compared to the IEC standard spectrum for $37^{\circ}$ tilt angle

Similarly, as we develop the framework and later in the standards development, we will use and build on the work done in the IEC 61853-4 [4] standard by including more representative standard reference climatic profiles that represent climate conditions of multiple areas and that will benefit energy rating calculations. One difficult task will be to evaluate the impact of cloudiness on the spectral distribution and develop cloudiness spectral standards. The application of measured irradiance spectra can allow for the evaluation of performance tests during cloudy periods. In recent years, the number of spectroradiometers deployed worldwide has increased considerably, and we aim to draw heavily on this new resource to better understand and represent field conditions. 


\subsection{Outdoor Process for Reference Cell Calibration and Characterization}

Several methods are used to calibrate reference cells, as described in [20]-[21]. Here, we will use and build on the work done in IEC 60904-4 [20], which is described as the "global sunlight method." This will maintain the outdoor calibration of reference cells traceable to the World Radiometric Reference (WRR). As stated in [19], the WRR is determined by a group of selected absolute pyrheliometers maintained by the World Meteorological Organization, located in Davos, Switzerland. In addition, a spectroradiometer traceable to the National Metrology Institute will be used to understand the spectral, temperature, and angle-of-incidence effects.

The feature of the outdoor calibration of reference cells is that all types of reference cells are related to a single reference under outdoor irradiance conditions instead of standard test conditions. The general calibration approach will follow IEC 60904-4, ISO 9846, and ASTM G167 [20], [23]-[24]. For instance, the proposed method will entail an absolute cavity radiometer with a $5^{\circ}$ field of view for direct normal irradiance (DNI) measurements and a diffuse pyranometer with a shading disk (Figure 3). The calibration of reference cells will include the temperature-corrected short-circuit current as well as the solar spectrum and spectral response of PV reference cells under clear-sky conditions from sunrise to sunset, thus encompassing all possible air masses for the day of calibration. As an example, the clear-sky conditions will be determined with a sky camera and will encompass long periods during which the sun is unobstructed by clouds and the sky is nearly cloudless.

This outdoor calibration method will attempt to address some of the sources of uncertainty in the method considering that PV reference cells have limited spectral response ranges, nonuniform spectral responses, and varying temperature and cosine response characteristics. Given the accuracy of the spectroradiometers, measuring the temperature of the reference cell, and knowing the effect of temperature on the spectroradiometers, the effect of changing spectrum can be determined. The reference cell must be tested under a variety of temperatures to get the proper temperature effect. The same can be said for the spectroradiometers. The reference cell temperature is normally monitored, and this can be used to normalize the temperature to $25^{\circ} \mathrm{C}$ by correcting for the temperature effect that was measured. Under a spectral lamp, the spectral responsivity of the reference cell can be determined. When convolved with the spectral data, the average spectral response of the reference cell can be determined. Once the information on the spectral and temperature effects is available, the angle-of-incidence effects can be estimated. This can be done when the reference cell is in a horizontal position, and the spectral distribution of the global irradiance can be measured along with temperature. After the temperature and spectral effects, the angle-of-incidence effects are evaluated. These effects can then be compared to a theoretical model.

Finally, the method will also attempt to include a comprehensive calibration uncertainty analysis by following the Guide to the Expression of Uncertainty in Measurement [22]. 

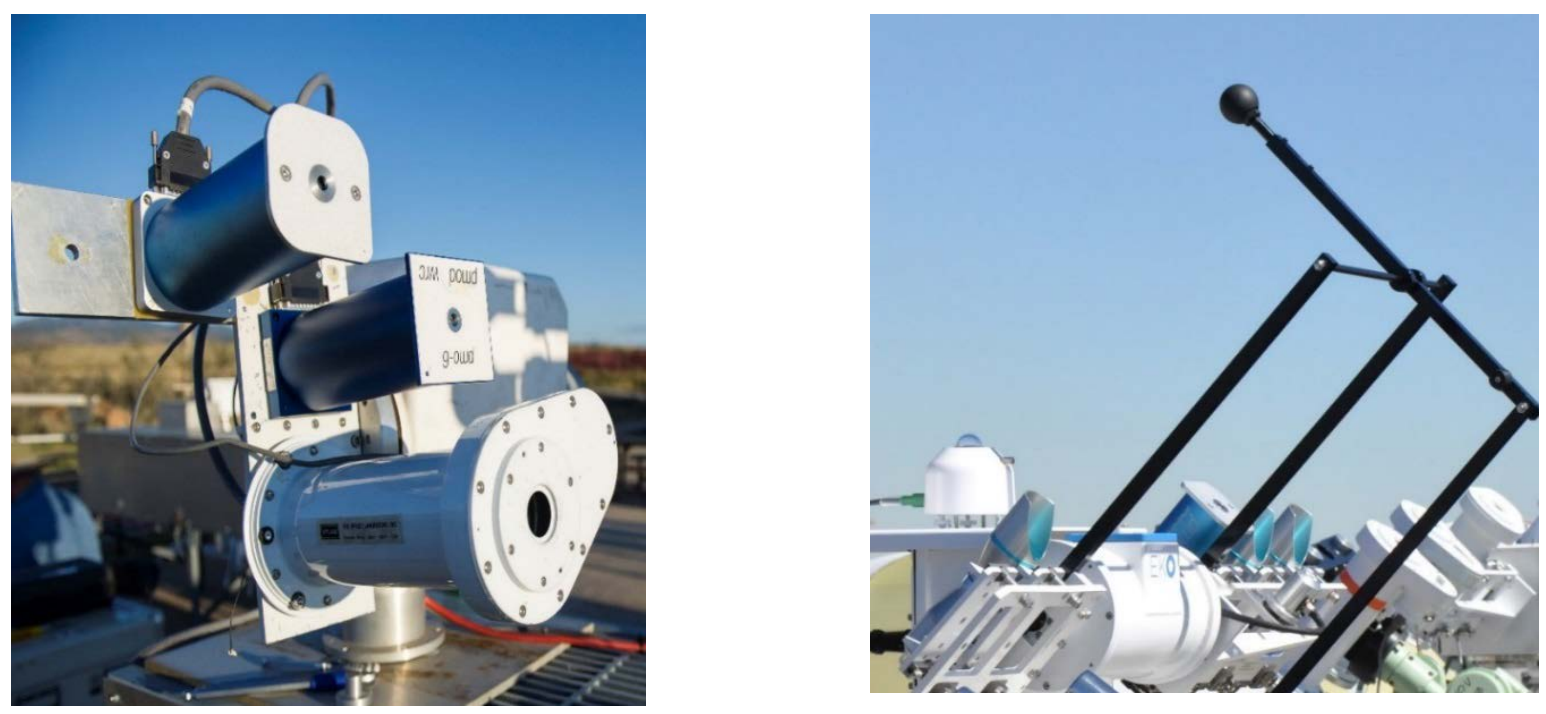

Figure 3. Absolute cavity pyrheliometer (left) and shaded diffuse pyranometer (right). Photos by Dennis Schroeder, NREL 22510 (left); and Tom Stoffel (right)

As an example, Figure 4 shows the calibration result for one silicon reference cell performed by NREL's Broadband Outdoor Radiometer Calibration (BORCAL) procedure in 2009. The BORCAL procedure follows a principle similar to that of ISO 9846 and ASTM G167 [23]-[24]. BORCAL provides responsivity in $2^{\circ}$ bins of solar zenith angle. Note that the uncertainty (U95) of the responsivity at $45^{\circ}$ is around $4 \%$ and that the spectral dependence of the reference cell varies slightly from one day to another, considering the two traces of the afternoon blue line (p.m.) during two different days.

To reduce this uncertainty, several approaches could be followed. One approach could use a specific filter, as explained in Section 2.2.1. Another approach could make use of parallel spectroradiometer measurements and reference cell characteristics, such as its cosine response and spectral responsivity for various temperatures. Together with the reference cell properties, the measured spectra allow for the calculation of the spectral mismatch and cosine errors for each measurement of the calibration data set. The reference cell measurement can then be adjusted to remove these biases. Hence, the calibration factor can be derived by comparing the adjusted reference cell measurements to the broadband reference measurements. 


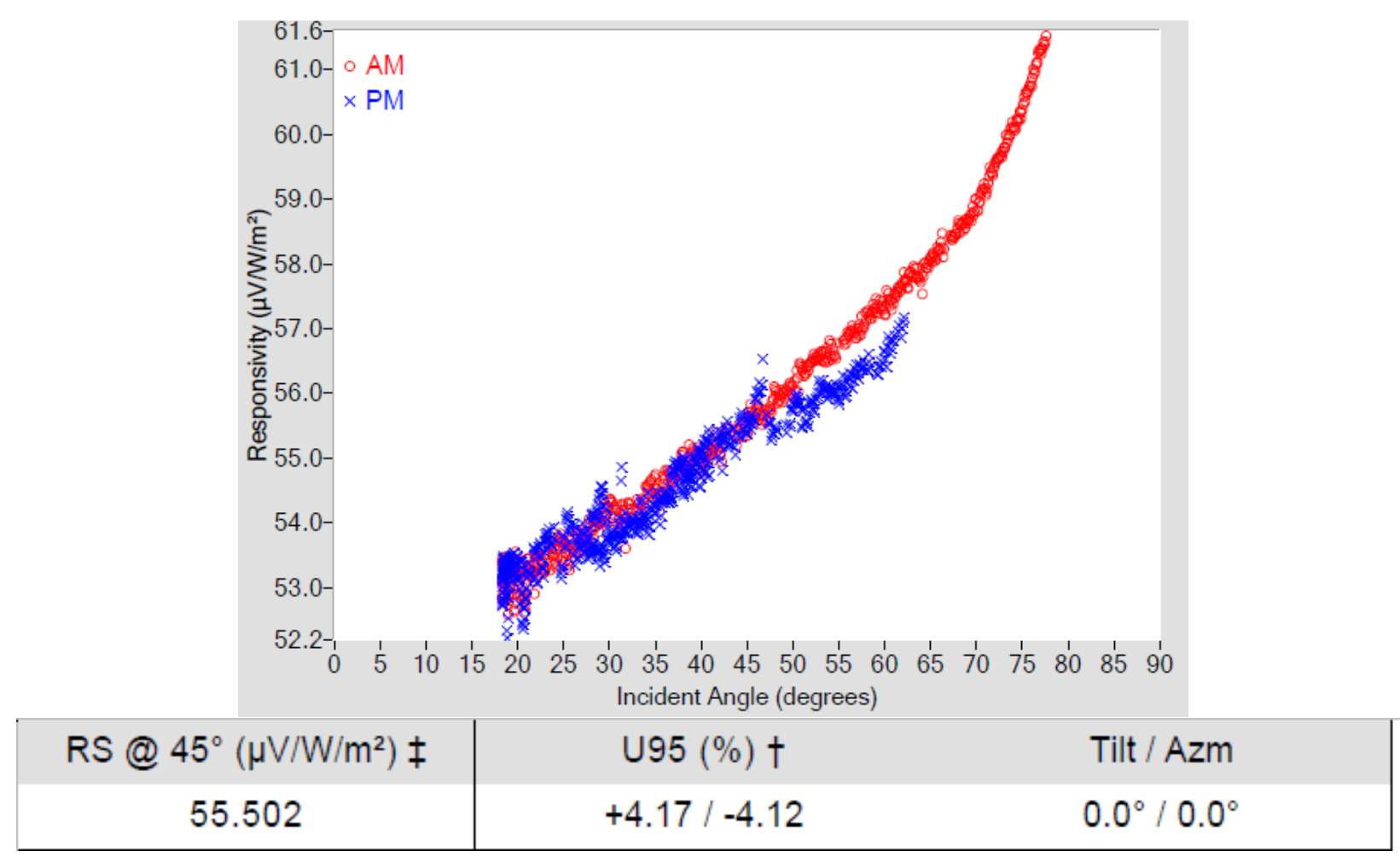

Figure 4. Calibration result for reference cell and associated calibration uncertainty. Illustration by Ibrahim Reda, NREL

Moreover, calibration of the reference cell in the manner that it is used (under various possible geometries) will also be considered by including a reference broadband diffuse on a tilted surface. Further, to understand the effect of tilt and orientation on the reference cell calibration, a spectroradiometer will be used to simultaneously measure the solar spectrum. The spectral measurement will enable understanding of the performance under various geometries. This type of calibration will also enable the determination of the temperature and angle-of-incidence effects.

\subsubsection{Develop Standard Filter for Reference Cells Calibration to PV Resource}

Historically, the calibration of reference cells that are used to assess the performance of PV systems has been done relative to the total solar resource under standard test conditions. The solar resource used to calibrate instruments that evaluate PV-based technologies covers a larger spectral range (300 $\mathrm{nm}$-approximately $3,000 \mathrm{~nm}$ ), which is a superset of the spectral irradiance range (300 nm-1,100 nm) to which current PV silicon-based technologies are sensitive. Performance guarantees based on the solar resource normally rely on a thermopile pyranometer mounted in the horizontal plane rather than the POA that matches the PV technology. This typically creates additional uncertainty in the performance estimates. To mitigate this issue (because reference cells are responsive to only a specific part of the solar spectrum to which a $\mathrm{PV}$ array is sensitive), it is recommended to evaluate the use of calibrated reference cells to measure the actual usable energy or PV resource. Several options can be used to "calibrate" reference cells. One possible option is to calibrate reference cells in a manner that is traceable to 
the International Systems of Units (SI) of irradiance through the WRR. This involves a reference absolute cavity radiometer equipped with a spectral filter $(300-1,100 \mathrm{~nm})$ and a reference diffuse reference cell or a diffuse pyranometer with a similar spectral filter $(300-1,100 \mathrm{~nm})$. The approach is described by the flowchart in Figure 5.

Several papers have been published comparing reference cells and thermopile pyranometers on horizontal, fixed, and tracking surfaces; see [6], [25]-[31]. These studies show several of the characteristics of reference cells that need to be established to fully characterize a reference cell. In addition, the shade and unshade calibration methods are difficult to apply to reference cells because they extend over a larger area compared to pyranometer sensors, and this increases the uncertainty in the calibration method.

An additional advantage of the filter method is to assist in establishing a spectral mismatch correction to the calibration method described in Section 2.2, which implements a broadband calibration. 


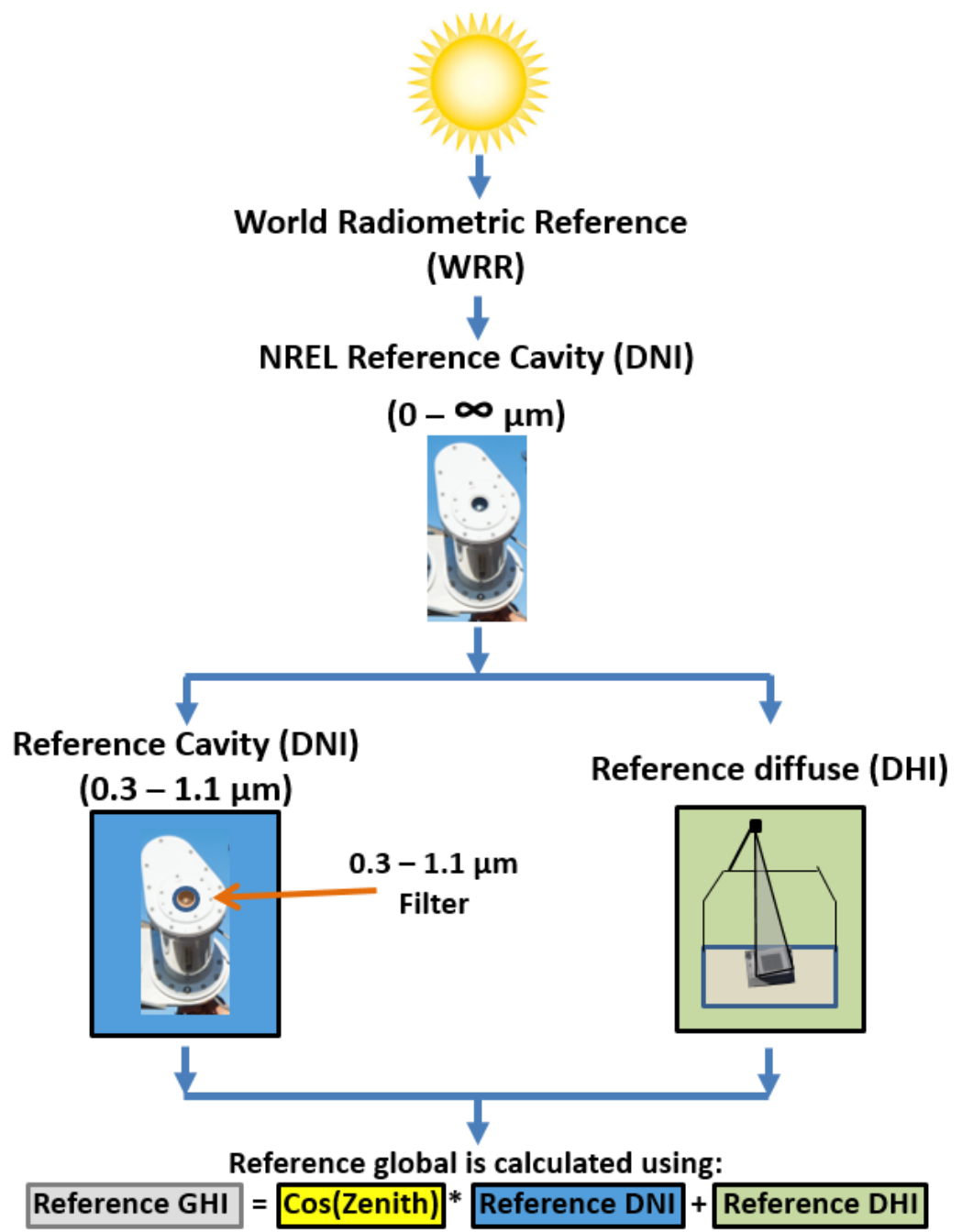

Reference global is then used to transfer the SI traceable calibration.

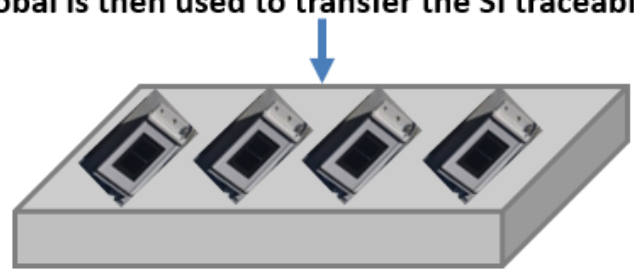

Figure 5. Flowchart illustrating the filter-based approach for reference cell calibration

\subsection{Develop Standardized Outdoor Process to Transfer Calibration from Primary Reference Cell to Secondary or Field Reference Cells}

This method will build on that described in IEC 60904-2 as the "calibration of secondary reference devices against a primary reference cell" using the "natural sunlight" method [20]. The calibration of the reference cells on a horizontal plane or for other orientations can be carried out using a "primary" reference cell, whose prior calibration would follow the method described in Section 2.2. This approach guarantees traceability to the WRR, but the primary and the unit 
under test should be same model with similar characteristics to reduce an unintended increase in uncertainty caused by differing device specifications.

Similar to the method described in Section 2.2, the outdoor transfer of the calibration represents outdoor environmental conditions at a specific moment and specific atmospheric conditions. Even though this represents a large number of variables, care can be taken to minimize environmental effects, such as ground albedo or shading, by ensuring that such effects similarly affect both the primary and reference cells under test.

\subsection{Develop Best Practices for Field Deployment of Reference Cells}

As described in [32]-[33], after a calibration procedure is developed carefully, a best practices document will need to define the deployment conditions, maintenance requirements, verification procedures, and calibration frequencies for the appropriate use of reference cells during field deployment. The core of the best practices document will address the use of the new extended characterizations of reference cells in the field. These characteristics include:

- Linearity of output over the range of irradiance values being measured

- Temperature dependence of the output of the devices over the range of temperatures to which the reference cells are subjected during deployment

- Spectral responsivity of the reference cells in the spectral band for which they are designed to operate compared to the specific solar spectrum to which they are exposed

- Directional response through all incidence and azimuth angles that the reference cells are expected to experience throughout the year. For consistency, a specific orientation of the reference cell should be determined and used.

Separate best practices might be developed for sophisticated users who have a need for the highest accuracy and for routine applications with more modest demands.

\subsection{Classification of Reference Cells}

ISO 9060 [34] provides classifications of pyranometers and pyrheliometers based on their specifications. The classifications of radiometers provide an easy way of referral in other standards and guides to facilitate the definition of a target measurement uncertainty and the process of uncertainty evaluation. The proposal here is to develop a classification standard similar to ISO 9060 but for reference cells. Comparison with these standards will inform the user about how accurate and reliable the reference cell can be when used to evaluate the PV resource. Obviously, developing this kind of standard will require effective engagement among all manufacturers of reference cells, users, calibration service providers, and research institutions. This will involve performing specification tests for variables that affect the accuracy of the reference cells. Many indoor and outdoor characterization methods have been published, such as those in [6], [25]-[31]. These specifications and reported results will be used as input to the standard.

Further, the standards for reference cells should be robust enough to determine when the technologies used for the reference cells render them less reliable for the evaluation of new PV 
technologies. These standards should be evaluated every few years to ensure that they are still adequate.

The classification system is a qualification process, and thus it needs to be based on a set of reference characteristics and their acceptance intervals for each reference cell. Evidence of conformity will need to be obtained from the reference cells' characteristics through testing the instrument design and through characterization of individual instruments during production or during a dedicated test. Depending on the reference cells' class and characteristics, the quality assurance system of the manufacturer should either guarantee (within a reasonable level of confidence) that instruments of a certain model comply with the requirement or verify compliance by testing a requirement for the individual instrument. 


\section{Challenges}

- The approach described for developing this framework starts with reference cell measurements; however, the PV models and the satellite-derived irradiance data must also be adapted to the reference cell measurements. The adaptation of the PV models is required to assimilate reference cell data. The adaptation of the satellite models is required for plant yield predictions or satellite-based performance evaluation. One method to adapt the PV models and satellite data is by developing methods that use spectrally resolved irradiance data.

- Another important challenge is how to account for the impact of cloudiness on standard spectra. Clouds tend to act as nearly ideal grey filters, thus depleting the clear-sky global horizontal irradiance (GHI) or GTI spectrum in a relatively spectrally constant way. One conceptually simple method to obtain a representative spectrum under realistic (partly cloudy) conditions during a long-term period is through a weighted average. Assuming a long-term average fraction, $\mathrm{Fc}$, of cloudy periods over a given region, the mean representative spectrum would be $\mathrm{Fc} T \mathrm{c}$ E $\lambda$ during the cloudy periods and $(1-\mathrm{Fc}) \mathrm{E} \lambda$ during the clear periods, where Tc is the average cloud transmittance, and $E \lambda$ is the spectral irradiance under scrutiny. This formulation is only a simple approximation, and detailed studies are needed to evaluate $\mathrm{Fc}$ and $\mathrm{Tc}$ over many regions. A similar approach has been used for adjustments to the diffuse component of rotating shadowband radiometers that use photodiode-based pyranometers [31].

- The development of consensus test methods to determine reference cell characteristics is a significant challenge. For instance, it is important to clearly identify the relationships among the temperature, spectral, and angle-of-incidence effects. Once the relationships are established, standardized test methods that detail the individual and aggregated effects will need to be developed.

- It is critical to understand the propagation of uncertainty while various calibration and characterization methodologies are being developed. As an example, for calibration under various tilts and orientations, the temperature and angle-of-incidence effects must be determined. This can be done, but the uncertainty increases if modeling is used.

- In the long term, additional research will be needed to evaluate to what extent the outdoor transfer of calibration described can be considered "universal" despite the interference caused by unavoidable solar spectrum variations when considering different seasons, locations, or geometries.

- Another challenge will be to harmonize existing methodologies/standards with the proposed standards so that consistency is maintained. This might require some changes to existing standards.

- The rapid evolution of various PV technologies will need to be closely monitored. It can be expected that the number of reference cells having specific spectral responses will continue to increase, thus making their regular calibration increasingly labor and time intensive. 


\section{References}

1. J. Meydbray, K. Emery, and S. Kurtz, "Pyranometers and Reference Cells: What's the Difference?," PV Magazine: Photovoltaic Markets and Technology (2012): 108-110.

2. A. Driesse, D. Dirnberger, C. Reise, and N.H. Reich, "Spectrally Selective Sensors for PV System Performance Monitoring," Proceedings of the 38th IEEE PVSC (2012): 3,294-3,299.

3. International Electrotechnical Commission (IEC), IEC 61853-1 (Ed. 1.0 b: 2011): Photovoltaic (PV) Module Performance Testing and Energy Rating-Part1: Irradiance and Temperature Performance Measurements and Power Rating (Geneva, Switzerland: 2011).

4. — IEC 61853-2 (Ed. 1.0 b: 2016): Photovoltaic (PV) Module Performance Testing and Energy Rating - Part 2: Spectral Responsivity, Incidence Angle and Module Operating Temperature Measurements (Geneva, Switzerland: 2016).

5. — IEC 61853-3 (Ed. 1.0 b: 2018): Photovoltaic (PV) Module Performance Testing and Energy Rating - Part 3: Energy Rating of PV Module (Geneva, Switzerland: 2018).

6. - IEC 61853-4 (Ed. 1.0 b: 2018): Photovoltaic (PV) Module Performance Testing and Energy Rating - Part 4: Standard Reference Climatic Profiles (Geneva, Switzerland: 2018).

7. ASTM, ASTM G173-03 (2012): Standard Tables for Reference Solar Spectral Irradiances: Direct Normal and Hemispherical on $37^{\circ}$ Tilted Surface (West Conshohocken, PA: 2012).

8. — ASTM G177-03 (2012): Standard Tables for Reference Solar Ultraviolet Spectral Distributions: Hemispherical on $37^{\circ}$ Tilted Surface (West Conshohocken, PA: 2012).

9. — ASTM G197-14 (2012): Standard Table for Reference Solar Spectral Distributions: Direct and Diffuse on $20^{\circ}$ Tilted and Vertical Surfaces (West Conshohocken, PA: 2012).

10. International Electrotechnical Commission (IEC), IEC 60904-3:2016: Photovoltaic Devices-Part 3: Measurement Principles for Terrestrial Photovoltaic (PV) Solar Devices with Reference Spectral Irradiance Data (Geneva, Switzerland: 2016).

11. International Organisation for Standardization (ISO), ISO 9845-1: 1992: Solar EnergyReference Solar Spectral Irradiance at the Ground at Different Receiving Conditions: Part 1: Direct Normal and Hemispherical Solar Irradiance for Air Mass 1.5 (Geneva, Switzerland: 1992).

12. W. Jessen, S. Wilbert, C. A. Gueymard, J. Polo, Z. Bian, A. Driesse, A. Habte, A. Marzo, P. R. Armstrong, F. Vignola, and L. Ramírez, "Proposal and Evaluation of Subordinate Standard Solar Irradiance Spectra for Applications in Solar Energy Systems," Solar Energy 168 (2018): 30-43, https://doi.org/10.1016/j.solener.2018.03.043, http://www.sciencedirect.com/science/article/pii/S0038092X18302755. 
13. K. Emery, D. Myers, and S. Kurtz, "What Is the Appropriate Reference Spectrum for Characterizing Concentrator Cells?" Proceedings of the 29th IEEE PV Specialists Conference (2002).

14. C.R. Osterwald, K.A. Emery, D.R. Myers, and R.E. Hart, "Primary Reference Cell Calibrations at SERI: History and Methods," Proceedings of the 21st IEEE Photovoltaic Specialists Conference (1990): 1,062-1,067.

15. C.C. Gonzalez and R.G. Ross, "Performance Measurement Reference Conditions for Terrestrial Photovoltaics," presented at the American Section of the International Solar Energy Society Annual Conference, Phoenix, Arizona (1980).

16. C.A. Gueymard, D. Myers, and K. Emery, "Proposed Reference Irradiance Spectra for Solar Energy Systems Testing," Solar Energy 73, no. 6 (2002): 443-467.

17. C.A. Gueymard, Smarts Code Version 2.9.5 User's Manual (Solar Consulting Services: 2005).

18. C.A. Gueymard, "Parameterized Transmittance Model for Direct Beam and Circumsolar Spectral Irradiance," Solar Energy 71 no. 5 (2001): 325-346.

19. C.A. Gueymard, "Direct Solar Transmittance and Irradiance Predictions with Broadband Models: Part II-Validation with High-Quality Measurements," Solar Energy 74: 381-395 (2003).

20. International Electrotechnical Commission (IEC), IEC 60904-4:2016: Photovoltaic Devices-Part 4: Reference Solar Devices: Procedures for Establishing Calibration Traceability (Geneva, Switzerland: 2016).

21. H. Mullejans, W. Zaaiman, F. Merli, E.D. Dunlop, and H. Ossenbrink, “A 2005 Comparison of Traceable Calibration Methods for Primary Photovoltaic Reference Cells," Progress in Photovoltaics: Research and Applications (2005): 13661-71.

22. Joint Committee for Guides in Metrology Working Group 1, Guide to the Expression of Uncertainty in Measurement (Paris, France: 2008), accessed September 2018: http://www.bipm.org/utils/common/documents/jcgm/JCGM_100_2008_E.pdf.

23. International Organisation for Standardization (ISO). ISO 9846:1993: Solar EnergyCalibration of a Pyranometer Using a Reference Pyrheliometer (Geneva, Switzerland: 1993).

24. ASTM, G167-15: Standard Test Method for Calibration of a Pyranometer Using a Pyrheliometer (West Conshohocken, PA: 2015).

25. A. Driesse, W. Zaaiman, D. Riley, N. Taylor, and J. Stein, "Indoor and Outdoor Evaluation of Global Irradiance Sensors," presented at the 31st European Photovoltaic Solar Energy Conference, Hamburg, Germany (2015). 
26. A. Driesse and W. Zaaiman, "Characterization of Global Irradiance Sensors for Use with PV Systems," Proceedings of the 42nd IEEE Photovoltaic Specialists Conference (2015): 1-5.

27. A. Driesse and J. Stein, "Site-Specific Evaluation of Errors and Uncertainty in Irradiance Measurements," presented at the 33rd European Photovoltaic Solar Energy Conference, Amsterdam, The Netherlands (2017), 10.13140/RG.2.2.14876.39044.

28. F. Vignola, C. Chiu, J. Peterson, M. Dooraghi, and M. Sengupta, "Comparison and Analysis of Instruments Measuring Plane of Array Irradiance for One-Axis Tracking PV Systems," Proceeding of the IEEE Photovoltaic Specialists Conference (2017).

29. F. Vignola, J. Peterson, C. Chiu, M. Dooraghi, M. Sengupta, and F. Mavromatakis, "Comparison of Pyranometers and Reference Cells on Fixed and One-axis Tracking Surfaces,” ASES National Solar Conference Proceedings (2017).

30. F. Vignola, J. Peterson, R. Kessler, M. Dooraghi, M. Sengupta, and F. Mavromatakis, "Evaluation of Photodiode-Based Pyranometers and Reference Solar Cells on a Two-Axis Tracking System," Proceedings of the IEEE Photovoltaic Specialists Conference (2018).

31. F. Vignola, J. Peterson, F. Mavromatakis, S. Wilbert, M. Dooraghi, and M. Sengupta, "Removing Biases from Rotating Shadowband Radiometers," Proceedings of SolarPACES (2018).

32. International Electrotechnical Commission (IEC), IEC 61724-1:2017: Photovoltaic System Performance-Part 1: Monitoring (Geneva, Switzerland: 2017).

33. ASTM, ASTM G183-05: Standard Practice for Field Use of Pyranometers, Pyrheliometers and UV Radiometers (West Conshohocken, PA: 2005).

34. International Organisation for Standardization (ISO), ISO 9060:2018: Solar EnergySpecification and Classification of Instruments for Measuring Hemispherical Solar and Direct Solar Radiation (Geneva, Switzerland: 2018). 